\title{
PRESENCIA DE ESPAÑA EN BRASIL
}

\author{
Julio G. García Morejón
}

Este tema exige una aclaración previa. No pretendemos enfrentar una vulgar cuestión de influencias, siempre, por cierto, harto difíciles de probar No se trata de analizar, microscópicamente, substratos, estratos y superestratos más o menos evidentes, aluviones de civilización y de cultura que, diseñadas con precisión las coordenadas etnológicas de un pueblo, hayan podido ir ahondando o ensanchando, en determinada dirección, cualquier vertiente racial o cultural. Si se desea entender, en sus debidas proporciones, un tema como este, de dificilísima investigación, tiene uno que plantearse la siguiente fórmula: ¿ España intervino en la conquista y colonización de Brasil de manos dadas con Portugal, y, por consiguiente, inyectó su sangre en las venas que circulan por el cuerpo de la nacionalidad brasileña, o fue un alud posterior de civilización y de cultura que, a semejanza de lo sucedido con otros pueblos que a estas costas arribaron, contribuyó en mayor o menor proporción al enriquecimiento de algunos aspectos de esta nacionalidad? Vamos a detenernos aquí un poco, que merece la pena.

La conquista y colonización de América, desde la cuenca del Río Grande hasta los confines de la Patagonia, es obra exclusiva, en su sentido civilizador y de cultura - haciendo abstracción de cuantos intereses pragmáticos, una $\mathrm{u}$ otra vez, hayan podido bastardear la meta cristiana civilizadora —, de España y Portugal. El hecho de que en una parte del Continente cuaje un vehículo de expresión lingüística diferente del que arraigó en otra fue, hasta cierto punto, un pequeño accidente, fundamental, sin embargo, para la formación de la conciencia cultural de las nacionalidades iberoamericanas. Pero el substrato espiritual de la conquista, en sus raíces esenciales, es el mismo. Camões fue quien mejor expresó el significado de estas raíces al dar a todo el orbe de habla portuguesa y española el nombre de Hispania, tan desvirtuado posteriormente por la retórica y por los intereses políticos conservadores. Pero hay que atenerse a la pureza con que lo pronunció el autor de $O s$ Lusíadas. En Camões se dibuja el vértice más sincero de las aspiraciones ibe- 
ristas de que se tiene noticia, y habría que llegar a los grandes escritores portugueses de la llamada generación de Coimbra para hallar ecos que se aproximen a esa pureza, en tono, sentido y sinceridad de propósitos. A cuatro siglos de distancia del gran épico portugués, Gilberto Freire, expresión cimera del pensamiento brasileño, ha dado nuevo sentido al vocablo camoneano al afirmar su brasilidad desde la misma ladera de aquellos grandes iberistas. Frases como las que vamos a citar sólo pueden entenderlas hombres sin prejuicios históricos o políticos, de mente abierta a los horizontes universales de nuestros pueblos hispánicos, los pueblos de habla portuguesa y española. Dice así el autor de Interpretação do Brasil: "Soy, desde antiguo, un estudioso de la literatura española, principalmente de las obras de ensayistas y místicos. La circunstancia de haber cursado mis estudios universitarios en ambientes anglosajones contribuyó a que, precisamente en aquella atmósfera, me sintiera yo desde mi adolescencia no sólo brasileño o lusobrasileño, sino hispano: un hispano que, para defenderse de la tentación de sucumbir a la idea de la superficialidad anglosajona o nórdica, tuvo necesidad de aferrarse a la tabla de esta condición básica: la de ser hispano. Y entonces me sentí partícipe - a través de la lengua española tanto como de la portuguesa - de una cultura rica en valores humanos - literarios, artísticos, filosóficos, religiosos - que aprendí a considerar como mi verdadera cultura materna. Más tarde pasé a sustentar la tesis basada, un poco, en esta experiencia personal mía - de que todo brasileño culto posee dos lenguas maternas - la portuguesa y la española - y también la de que el Brasil es la nación más hispánica del mundo, por la razón de que su formación fue española y no únicamente portuguesa. Ninguna otra nación hispánica ha sido doblemente hispánica en este sentido"

Si ahondamos en tal concepto y traemos a colación los sueesos históricos que motivaron la independencia política de tos dos pueblos peninsulares ibéricos, podríamos llegar fáciłmente a la conclusión de que dicha independencia fue siempre, en sus principios, más fruto de la fatalidad que de otra cosa. La fatalidad contribuyó poderosamente a que España y Portugal se constituyesen en dos naciones distintas. Claro que es así como con frequencia suele escribirse la Historia. Veámoslo, pues, aunque a grandes rasgos: la mayoría de los enlaces dinásticos entre príncipes y reyes de España y Portugal tenían como meta da unión de ambas coronas. Don Alfonso Henriques dicta la primera línea de este capítulo; de su matrimonio con doña Mafalda de Mauriana y Saboya tuvo una hija, doña Urraca, la cual contrajo matrimonio con Fernando II de León. Digamos que el interés del ensanchamiento fronterizo estaba en primer plano; no importa. Detrás de él vendrán otras cosas. Pues esos caprichos cortesanos colocaron siempre en riesgo de fusión a las coronas ibéricas. La ba- 
talla de Aljubarrota marca una huella importante en dichas aspiraciones. Oliveira Martins demuestra que en Aljubarrota nace Portugal como nación independiente, sin el pecado de la dinastía de Borgoña. Sólo a partir de este instante - escribimos hace ya algunos años, en nuestro libro Unamuno y Portugal - cualquier intento de unión peninsular podría comenzar a tener un vago sentido iberista. Portugal siente que se le sube al corazón y a la cabeza su destino, su ser nuevo, su ser real. Es la hora en que le llama de lejos "un dúvio tentador - o Mar!", como diría en una obra humilde y lírica, titulada Caminos de Portugal, Martín Domínguez Barberá. El recuerdo de Aljubarrota conduce a los portugueses al fracaso de la batalla de Toro, en 1476. João Ameal, en su História de Portugal, resume así el conflicto y los resultados: lo que triunfa en Toro "é a tenacidade, a intransigência nacionalista de Dona Isabel - que neste lance personifica a vontade de Castela, de se eximir à soberania estranha, como em 1383-85 o Mestre de Avis e Nuno Alvares personificam idêntica vontade de Portugal. Melhor: o que triunfa é a própria natureza das coisas, oposta à unificação da Península" En 1490, el príncipe Dom Afonso, hijo de Dom João II de Portugal, contrae matrimonio con la infanta Isabel, hija de los Reyes Católicos. Un año después, sin embargo, muere el príncipe portugués de una caída de caballo. "Este incidente - advierte Oliveira Martins -, imprevisto, da morte do Príncipe, é um dos que obrigam a meditar sobre o valor do acaso na História" Dom Manuel I fue un obstinado. Se casó tres veces, y las tres con princesas españolas. Para colmo, su hija Isabel contrajo matrimonio con el Emperador Carlos I, hermano de doña Leonor de Castilla, su tercera esposa. Carlos I y João III se ceden las hermanas. Cree Oliveira Martins que "havia um acordo sobre essa questão da unidade do corpo peninsular; e porventura unânimes no princípio, deixaram ao acaso decidir entre os descendentes das duas dinastias" El acaso actuó así: Dom João, hijo de Dom João III, heredero presuntivo del trono portugués, se une a doña Juana, hija de Carlos I. De tal enlace nace el infortunado Dom Sebastião, heredero del trono, al que Felipe II, ambiciosamente, le había ofrecido ya la mano de su hija Isabel Clara Eugenia, pero a quien no se la otorgaría hasta conocer los resultados de Alcazarquivir. Hay quien asegura que el monarca español estimuló la catástrofe. Dom Sebastião muere en combate y sin descendientes. El acaso es nuevo agente de revolución. Los sesenta años que transcurren desde la incorporación de la corona portuguesa a España hasta que con Felipe IV adquiere el país hermano su plena soberanía - no sin subyugarse políticamente a Inglaterra - , son sumamente importantes para entender la tesis que venimos defendiendo: la de la participación absoluta de los españoles, al lado de los portugueses, en la formación étnica de Brasil y en el desarrollo de la historia co- 
lonial brasileña y de la conciencia cultural de este pueblo. Pinto do Carmo, en un librito titulado Presença da Espanha, subraya que "o concurso castelhano na ajuda de nossas coisas materiais e espirituais aparece-nos na época colonial; surgiu como decorrência de sua projeção na Península Ibérica quando unificava um só povo, preponderância essa que perdurou por algum tempo, mesmo depois do surgimento da cultura lusa, com a separação das nacionalidades, após o XI século. Passada a fase primeira, não diminuiu; manteve-se, até hoje, embora discretamente. Enquanto outros nos chegaram como hóspedes, que não escondem a sua presença, pretendendo lugar especial e encontrando quem lhes aumentasse os préstimos, dispensou o castelhano qualquer deferência e preferiu marchar ao nosso lado sem solicitar além do que obriga a educação para com o bom amigo que, para ajudar, nos estende a mão"

La presencia de España en Brasil, yendo ahora a los hechos históricos concretos que se conocen, es anterior a la de Portugal. Nada tiene esto de extraño ante lo que acabamos de afirmar en las páginas precedentes. Y mucho menos si se tiene en cuenta que en ese vaivén atlántico que se inicia con Colón eran las naves españolas las más dadas a esas singladuras. A los portugueses les interesó siempre mucho más la ruta tradicional por las costas africanas. Así, pues, nada debe extrañarnos que navegantes españoles arribaran a estas playas antes que Pedro Alvares Cabral. Alonso de Ojeda, Vicente Yáñez Pinzón y Diego de Lepe arribaron a estas costas durante los primeros meses del año 1.500 , según relatan y confirman los historiadores más serios de Brasil, aunque no se hayan precisado con exactitud los lugares de desembarque. En realidad, tales episodios no tienen mucha importancia, ni la oficialización del descubrimiento de Brasil por Cabral destruye nuestra teoría, pues de una $\mathbf{u}$ otra forma está claramente comprobada la raíz española, al lado de la portuguesa, en el suelo brasileño. Tenía que haber un descubrimiento oficial. La Historia exige nombres y fechas. Y este nombre cupo a Pedro Alvares Cabral. Los sucesos posteriores, es decir, la adscripción del país a Portugal, resultante de los avatares históricos, de las voluntades individuales dominantes, tanto de un lado y de otro del Océano, del destino, en una palabra, dieron autenticidad y rango pleno a los hechos que argullosamente proclaman los historiadores del país.

Interesa destacar este factor: mientras que los exploradores procedentes de otras latitudes - franceses, ingleses, holandeses, por ejemplo - sólo venían con el propósito exclusivo de retornar a sus tierras cargados de "pau brasil" y otras riquezas, los españoles, aun teniendo en cuenta las excepciones, fueron, en su inmensa mayoría, quedándose por aquí. Su sentido de la conquista fue mucho más 
civilizador. El español vino siempre para morir en esta tierra y producir, con su savia, nuevos esquejes de nacionalidad americana. El español que aquí llegaba - y el fenómeno se ha venido repitiendo hasta hoy (quien esto escribe es prueba cabal de la afirmación) - se nacionalizaba de inmediato; es decir, participaba sin dolor de la vida local que aquí encontraba; contribuía a formar esa vida local; se confundía con la tierra; se integraba rápidamente en el paisaje, y formaba, a semejanza de los portugueses, una unidad de cuerpo y alma con el país. Su destino empezaba a ser un destino brasileño desde la llegada. En esto reside la grandeza de la colonización de América por los pueblos de la Península Ibérica. En la soberanía del mestizaje estriba la realidad histórica de los pueblos de la América lusoespañola de nuestro tiempo. Nuestros pueblos se confundieron con los pueblos que aquí había. El proceso colonial fue, pues, el mismo para todo el Continente. Las variantes que posteriormente podrán advertirse - es decir. las singularidades regionales - se deben, en especial, a los puntos de vista diferenciadores a veces impuestos por la política y las ordenaciones metropolitanas, así como a los innumerables poderes locales que se fueron instalando en América, acosados por una serie de imperativos, abismos imponderables que, de una u otra forma, establecían las diferencias y los contrates: escasísima población, desproporcional a la inmensa extensión geográfica; impresionantes distancias y no menos, como consecuencia de ello, dificultades de comunicación, factores que más tarde contribuirían a una serie de dependencias de potencias extranjeras que adulteraban, en virtud de orientaciones políticas pragmáticas, el sentido y la norma humanística de la civilización ibérica.

Pero el acaso va a actuar una vez más en pro de las relaciones entre los españoles y Brasil, y ahora con una fuerza y una solidez indiscutibles. La historia empieza con la incorporación de la corona portuguesa al imperio de Felipe II, como consecuencia de las pendencias dinásticas que motivaron la muerte de Dom Sebastião en Alcazarquivir. Durante sesenta años, como se sabe, Brasil queda bajo el designio de España. Y lo que podría haber sido o significado un retroceso para la Colonia fue, como todos han reconocido, un extraordinario avance, un acontecimiento trascendental, que mudó de tal forma "a vida e o destino do Brasil, que cumpre seja feito trabalho de pesquisa mais cuidadoso procurando a explicação dos fatos ocorridos durante aqueles 60 anos", leemos en la História Geral da Civilização Brasileira, dirigida por Sérgio Buarque de Hollanda. Si hubo o no una deliberada política de Felipe II y sus descendientes en relación a Brasil - detalle que los historiadores no han logrado aclarar por completo - , tal cuestión poco muda el aspecto que tomaron las cosas por aquí o el rumbo que condujo al país a los destinos de gran nación con que hoy quiere imponerse en el mundo. No 
es posible que los hechos se sucedieran al azar durante los sesenta años filipinos. Si se tiene en cuenta el carácter de Felipe II, su constante estudio y análisis de todos los problemas políticos y administrativos del Imperio, su celo excesivo y riguroso escrúpulo en la conducción de la cosas de gobierno, su manera absoluta e imperativa de poner él mismo su dedo en todos los negocios del Estado, por más insignificantes que fuesen - a diferencia de sus sucesores, que dejaron en manos de vanidosos e incompetentes validos el timón del barco - , no habrá duda de que un problema como el que representaba Brasil en el contexto de la política ultramarina de los Austrias no se podría haber dejado andar a la deriva. Si se tiene esto en cuenta, es imposible dejar de pensar que cuanto sucedió en el país durante esos sesenta años y, en especial, durante el reinado de Felipe II, no fuese fruto de una política de cálculos y de intereses. El fortalecimiento del Brasil Colonia contribuía al fortalecimiento del Continente, y el fortalecimiento del Continente hacía más temible a la metrópoli, que ya iba perdiendo sus fuerzas en guerras simultáneas, distantes unas de otras geográficamente. Desde este punto de vista, Brasil debe a España y, concretamente, a la visión de Felipe II, su horizonte de grandeza continental. Mientras España actuaba política y bélicamente, asumiendo la responsabilidad de las grandes decisiones e impidiendo a cualquier costo que países extraños, y con fines ilícitos, deteriorasen las bases colonizadoras ibéricas, tuvo suficiente tino el Monarca de conservar en la colonia a las autoridades portuguesas y de aceptar las sugerencias del Consejo de Portugal. Es significativo el hecho de que un hombre como Martin de Sá, gobernador de Río de Janeiro, considere a Portugal no como un país conquistado sino como una tierra de la corona de España. Es necesario citar de nuevo la História Geral da Civilização Brasileira, que añade a lo ya dicho anteriormente: "Sem dúvida, fazia parte dos planos espanhóis preservar "espanhol o que é espanhol e português o que era português" na América (apesar da união das duas Coroas) Quanto a esse desígnio, estamos certos de que a Coroa espanhola se mostrou particularmente ciosa. O que resultou deste vasto período de 60 anos, em matéria de contatos entre as duas partes, muitas vezes pode surpreender pela exuberância e importância dos acontecimentos. Não há que negar a coincidência do período dos Felipes no Brasil com a mudança na orientação da colonização e da penetração. Coincide com o sistema espanhol da colonização mais no interior na mudança do sentido da penetração colonizadora no Brasil. Coincide com esse período o incremento da expansão provocada pelo gado, com a penetração e a conquista do Nordeste, com a expulsão dos franceses, com o impulso que irá provocar o bandeirismo. $O$ período dos Felipes foi um período de penetração e conqusita. Desde a ocupação da Paraíba (1584) até a do Pará (1616) há uma histó- 
ria pouco explorada mas de grande importância. Capistrano de Abreu julgava a história da conquista do Nordeste uma das partes mais importantes de toda a história do Brasil. Por exemplo, importante é o fato de o povoamento realizado nesse período, em função das conquistas no Nordeste durante o século XVII, só mais tarde se haver posto em contato com o litoral . A colonização posterior da região do NE foi obra muito vasta, realizada, principalmente, por gente originária da Bahia, durante o século XVIII. Somente em fins do século XVIII é que foi terminado o caminho entre Maranhão e Bahia, pois o Maranhão, devido aos ventos na costa NE, tinha a navegação marítima impedida durante a metade do ano. Parece que a mudança da forma de povoamento durante o domínio espanhol (passou a ser do interior para o litoral) forçou a abertura de caminhos internos durante o período em questão e mesmo após a Restauração portuguesa. Ficou a "marca espanhola" gravada na localização e multiplicação de cidades novas e mesmo no modo pelo qual se desenvolveram mais tarde" La cita es larga, pero compensadora. Y prosigue el historiador brasileño: "Além do povoamento, penetração e fundação de cidades, da abertura de caminhos (fatos todos realizados no período dos Filipes), um aspecto muito importante desta época foi a conquista de regiões onde os franceses estavam fincados e apoiados em ótimas relações com os indígenas. Os franceses faziam grande progresso, lidando com contrabando de drogas do sertão e no comércio das mesmas. A forte reação nesse sentido, durante o período espanhol, decidiu a grande incógnita que perdurava ainda no começo do século XVII: o Brasil seria português ou francês? Destacam-se nesta empresa Diego Flores Valdés, comandante da esquadra espanhola, e Castejón, um espanhol de grande bravura pessoal, que deteve os Potiguar que, armados pelos franceses, atacavam o forte erguido por Valdés" Vicente Tapajós, en su História do Brasil, al enfrentarse con episodios de este tipo, reconociendo lo que esos años contribueron al ensanchamiento del terrorio brasileño, señala que tales hechos comenzaron a engendrar en el espíritu de los ciudadanos de estas tierras la formación y el desarrollo de la idea nacional.

Podríamos añadir otros conceptos semejantes a los que acabamos de citar, de otros historiadores. Hélio Vianna, por ejemplo, acentúa la importancia de la expansión territorial y el vaivén de españoles y portugueses desde el litoral al interior y viceversa, a través de las Entradas y Bandeiras: "Assim, enquanto muitos espanhóis com facilidade se estabeleciam em povoações brasileiras, o que antes lhes era defeso, por seu lado muitos luso-brasileiros, em Entradas e Bandeiras, também penetravam em regiões anteriormente atribuídas à Espanha, com isso obtendo títulos de prioridade e posse que seriam respeitados pela diplomacia posterior. Atingiam, desta forma, as futuras fronteiras terrestres do Brasil" En estas condiciones, era 
imposible un estencamiento étnico brasileño a base de simientes exclusivamente portuguesas. La transformación del elemento humano de la Colonia, durante los sesenta años filipinos, ha sido ya reconocida por historiadores y etnólogos del país. La presencia de los españoles, tanto en el norte como, principalmente, en el sur de la Colonia - debido, en esta parte, a la atracción que ejerció siempre sobre ellos la región del Plata - , fue un elemento catalizador que impulsó el desarrollo de Brasil. El incremento de la vida urbana, fruto de la creación de nuevas ciudades, en cuya gestación intervinieron destacadamente los españoles, es sólido argumento para demostrar la capacidad del español de dar un norte claro a la colonización sin prescindir nunca de su cooperación e integrando este hombre de la Península al paisaje. Aracy Amaral ha demostrado recientemente cómo la presencia española en São Paulo, por ejemplo, en donde hasta hoy la huella hispánica prepondera, se impone desde los primeros momentos de la instalación de la Capitanía de São Vicente, e incluso antes de la llegada de Martim Afonso, con la presencia de náufragos españoles y portugueses que vivían en este litoral. En su estudio sobre $\boldsymbol{A}$ hispanidade em São Paulo, señala la autora citada que la presencia de España en São Paulo persistiría hasta fines del siglo XVII de una menera significativa, "permanecendo depois através da integração de diversas famílias e seus descendentes, no planalto de Piratininga. Certos hábitos mesmo persistiram ainda em manifestações culturais - como construções - que os paulistas levam a Minas e Goiás no século XVIII. Ainda no século XIX, St. Hilaire registraria entre a população paulista peculiaridades espanholas" Demuestra a continuación cómo en la arquitectura de esta región se registran indiscutibles influencias de España, ora directamente, ora a través de los países hispanoamericanos: casas grandes, con grandes corredores, con columnas de madera, de planta simétrica cuadrada, con elementos decorativos, con pórticos en las dos faces de la casa, independientes de la estructura del tejado, cierto carácter monumental, y concluye: "De fato, a imponência é um aspecto de várias casas seiscentistas e setecentistas dos arredores de São Paulo.

São de uma majestade tipicamente espanhola e isso apesar da rusticidade evidente de sua construção, de sua simplicidade despojada. Essa construção tem "raça", teve um risco, uma traça" Si se lee lo que Sérgio Buarque de Hollanda ha escrito en su libro Raízes do Brasil sobre la organización y estructura de la ciudad y casa construída por los españoles en América, se podrá ver la procedencia de las observaciones hechas por Aracy Amaral sobre las construcciones paulistas. En ese mismo estudio, refiriéndose concretamente a determinados personajes, añada esta autora: "Assim, aos primitivos habitantes do núcleo inicial onde inexistiam europeus em 1554, aos poucos se uniam os procedentes de São Vicente, e além 
dos indigenas que a ela vieram ter, espanhóis de diversas procedências, tendo os primeiros habitantes se casado muitos deles com descedentes de João Ramalho e Tibiriçá. Parte dos espanhóis procedia da Espanha, sobretudo os que vieram participando de armadas que lutaram contra os holandeses na Bahia. Neste caso se encontra Bartolomeu Bueno, chamado "o sevilhano", carpinteiro de ribeira, chegado ao Brasil em 1581. Outros castelhanos que aqui chegaram da Espanha, via Bahia, foram os irmãos Redón, em armada de Castela para combater os holandeses. Estes se casariam com duas irmãs filhas de Amador Bueno, tendo o primeiro recebido por dote terras na região do hoje bairro de Santana, depois doadas ao Colégio de São Paulo e incorporadas ao que seria posteriormente a Fazenda de Santana dos Jesuítas. Nem todos os castelhanos que chegavam a São Paulo vinham de além-mar. Devido ao intenso intercâmbio por via terrestre entre Paraguai e São Paulo, houve vários casamentos entre os que iam daqui e espanholas que lá viviam. Na década de 30 do seiscentos, grande foi o número de castelhanos que, após a destruição de Guairá pelos paulistas (1628), veio para Piratininga" En la capital paulista, según han señalado Alfredo Ellis y otros historiadores, se llegó a establecer una élite castellana que llegó a imponerse al propio Rey, y por poco no proclaman rey de São Paulo a Amador Bueno, cuando Portugal se separó de España. Este mismo historiador, en sus Capítulos da História Social de São Paulo, relaciona una serie de familias procedentes de Andalucía, León, Extremadura y otras regiones de España que se asentaron en São Paulo, y Arthur Ramos señala que "muitas estirpes paulistas que chegaram até os nossos dias, provém desses troncos primitivos, vários destes misturados posteriormente a elementos lusos e mamelucos" Pero no se ciñe solamente a São Paulo el capítulo de la influencia hispánica en Brasil. En su Introdução à Antropologia Brasileira, el ya citado historiador Arthur Ramos se refiere a otros troncos étnicos surgidos en el sur del país como consecuencia de la presencia de españoles en esas costas; relaciona el nombre de los náufragos de la expedición de Juan Díaz de Solís, que regresaba del Río de la Plata en 1615 y que arribaron al litoral de Santa Catarina, así como muchos otros navegantes y exploradores al servicio de España que poblaron dicho litoral, constituyendo a mediados del siglo XVI un gran núcleo de población en esta región. Señala Arthur Ramos que la historia étnica de Rio Grande do Sul es sensiblemente la misma de Santa Catarina, y afirma categóricamente - con lo que se comprueba la tesis que defendimos al principio de este ensayo que "oscilando entre as soberanias portuguesa e castelhana, seu solo foi percorrido no início de sua história por elementos das duas nações", y concluye: "a influência do espanhol histórico não é, pois, para desprezar-se, principalmente nas zonas marginais, como no sul e 
oeste, aberto à sua penetração. Etnicamente, esse espanhol vem das províncias meridionais, como a Extremadura e Andaluzia. Esse pertence ao velho stock dolicocéfalo moreno, da raça mediterrânea, e racialmente não acrescentou nada novo ao substrato luso. Culturalmente, sua influência foi maior, especialmente no Rio Grande do Sul. O gaúcho é o símbolo histórico desse encontro de culturas"

Carlos Xavier Paes Barreto, en su estudio sobre Os primitivos colonizadores nordestinos e seus descendentes, después de subrayar el hecho de que la familia nordestina brasileña proviene mediatamente de Castilla, por considerar españoles los troncos portugueses de los "Abreu", "Aguiar", "Albuquerque", "Almeida", "Andrade", "Azevedo" y otros, observa el hecho de que varias familias oriundas de aquella región de España llegaron a Brasil a través de la isla de Madeira, y, entre ellas, los descendientes del Conde de Favela y de João Rodrigues Mondragão. "Diretamente de Espanha - añade diversos elementos permaneceram em Pernambuco, como sejam Gonçalo B. Valcasser, João Nabalhas e João Ramires"

No podríamos dejar al margen - por lo que representa desde el punto de vista del desarrollo cultural y espiritual del Brasil - el capítulo que se refiere a la acción de los jesuitas en estas latitudes. Aunque todos saben que la idea catequística de esta orden transcendía todo tipo de regionalismo o nacionalismo ( $\mathrm{y}$ hay mucho menos diferencia entre un jesuita francés y un jesuita portugués que entre cualquier otro tipo de hombre de uno y otro país, por ejemplo) - siendo el credo jesuítico dibujado dentro de coordenadas católicas imperialistas -, no podemos dejar al lado el hecho de que en la catequesis de los indígenas de Brasil y, más tarde, en las relaciones políticas y religiosas y sociales de las gentes, intervinieron muchos jesuitas españoles al lado de los portugueses. La cooperación espiritual de los españoles en la colonización del país es indiscutible, "presentándo-se siempre - como lo exalta Gustavo Barroso - con aquel su tradicional espíritu de devoción, de estoicismo, de caballerosidad. Esto se refiere - aclara - a la tarea coronada por los jesuitas castellanos, mártires unos, héroes otros, y todos entregados a la árdua empresa de catequizar a los indígenas brasileños, desarrollando un trabajo áspero e insano, plagado de peligros de toda especie" Hay que destacar la ingente tarea llevada a cabo por hombres como Gregorio Escribano, Juan de Mallorca, Juan de San Martín, Fernán Sánchez, Francisco Pérez, Esteban Zurara y Antonio Blázquez, que murieron víctimas de la insana actividad francesa en la expedición de Ignacio de Azevedo. Sobre Antonio Blázquez escribió Alberto Silva en Dos españoles en la Historia del Brasil: "Blázquez fue el primer profesor de Latín del Brasil. Peregrino por "tabas" indígenas, persuadiendo, con su palabra elocuente, a decenas de "bugres", a fin de 
que "miles de almas se convirtiesen a su Dios, abandonando ritos y costumbres tan abominables". La obra del catequista Antonio Blázquez tuvo elevada significación moral. Los jesuitas castellanos realizaron una meritoria obra en beneficio de la gente y de la tierra brasileña" Es necesario destacar también, por otro lado, la acción de los jesuitas españoles contra las incursiones que los moradores de la Capitanía de San Vicente hicieron por toda la región del Guairá, a fin de arrebatar todos los indios de las reducciones, sin que obtuvieran resultados en sus protestas. Mención especial merecen, entre los jesuitas españoles que dejaron una huella visible en la formación espiritual y cultural de Brasil, en primer lugar, José de Anchieta, el fundador de la ciudad de São Paulo, y uno de los pilares fundamentales de la cultura y de las letras coloniales. Es bastante extensa la bibliografía sobre el famoso taumaturgo, al que en 1965 se le prestaron homenajes nacionales por iniciativa de la Presidencia de la República de Brasil, ocasión en que, presentado por Júlio de Mesquita Filho, pronunciamos una conferencia sobre su obra lírica en el Pátio do Colégio. En segundo lugar, y entre otros misioneros de en 1597 y fallecido en Lima en 1675, autor de una obra importante titulada Nuevo descubrimiento del gran Río de las Amazonas (1641), en la que relata sus aventuras y experiencias al lado de Pedro Teixeira en su incursión por el río Amazonas; Juan de Azpilcueta Navarro, que fallecio en Bahia en 1557, uno de los primeros, sino el primero, que asimiló el lenguaje de los indígenas, a semejanza de Anchieta, y que llegó a escribir en esa lengua algunas de sus obras de catequesis, también a semejanza del fraile fundador de São Paulo.

A partir de la restauración del dominio portugués, el cuadro que se dibuja en Brasil es otro. Esta tierra pasa a ser colonia exclusiva de Portugal. Ingleses y holandeses comienzan a sacar provecho de ella, el provecho que venían intentando sacar desde el descubrimiento de la misma. Se suceden, a partir de la guerra de Sucesión española, las firmas de varios tratados, como el de Utrech, que establece la frontera de límites en el río Oiapoque. La colonia portuguesa del Sacramento permanece aún en poder de España, hasta que por el Tratado de Utrech (1715) es restituida a Portugal, la cual va a sufrir una nueva investida en 1735 por parte del Gobernador de Buenos Aires. Las circunstancias imponen la firma de un nuevo Tratado, el de Madrid, en 1750, en cuya elaboración interviene inteligentemente Alexandre de Gusmão; a cambio de la colonia del Sacramento, España ofrece a Portugal el territorio de los Pueblos de las Misiones. Todos estos Tratados, y los que aún van a sucederse, como el del Pardo, en 1761, que anula las cláusulas finales del de Madrid referentes a la pérdida por parte de España de los territorios de América del Sur; o el de París, en el mismo año, en virtud del cual se le devuelve a Portugal la Colonia del Sacramento, que vuel- 
ve a ser asediada en 1777 , lo que va a exigir un nuevo Tratado, el de San Ildefonso, hasta que, por fin, el de Badajoz, en 1801, recupera para Portugal la región de los Siete Pueblos de las Misiones y concede a España la Colonia del Sacramento; todos estos Tratados, que sólo influyen en la cuestión de límites, sirven para agitar los medios diplomáticos, pero en nada van a contribuir a la mudanza de la fisonomía de Brasil desde el punto de vista étnico. Todas estas discusiones de fronteras no van a impedir, de manera alguna, el desarrollo normal de las sociedades hispano-portuguesas e indígenas que se han ido instaurando en la región. Se han sucedido ya muchas generaciones desde que Pedro Alvares Cabral llega a Brasil, y por las generaciones que advienen a la vida social, política, cultural y económica del siglo XVII corren sangres mezcladas en cuyas moléculas es difícil precisar con exactitud el porcentaje de sangre española. No hay duda, sin embargo, de que dicho porcentaje es muy elevado, caracterizándose, en cantidad, por lo menos, como en segundo lugar después de la sangre portuguesa. Basta observar los hechos históricos que hemos tenido el cuidado de subrayar y los resultados alcanzados por la intervención de España y de los españoles en la vida del país. He aquí por qué afirmamos, al comienzo de este ensayo, que la obra colonizadora en Brasil no fue obra exclusiva de un pueblo, sino el empeño decidido y abnegado de gentes de una misma raza, la española y portuguesa, que se dividían las tareas en los avatares de la conquista americana, y en cuyos resultados el azar contribuyó en ocasiones a ciertas anticipaciones en la llegada a unas u otras playas. Así como por las venas de los portugueses y españoles corre la sangre ibera, celta, romana, goda, árabe, judía, etc., por las venas de las primeras gentes de Brasil - proclamando a lo lejos esas raíces etnológicas y antropológicas - corre sangre andaluza, castellana, leonesa, extremeña, portuguesa del Miño, de la Beira, del Algarve, de la isla de Madeira, etc., es decir, una misma sangre, diferenciada por los matices regionales y la imposición de diferentes substratos civilizadores, la cual entra pronto en ebullición al contacto con la sangre indígena. Está cuajando, en la estereotipia que forma este paisaje, una nueva organización biológica, una nueva célula, y nuevos mestizajes dan origen a nuevas formas de existencia del ser americano, mejor dicho, iberoamericano. Lo difícil es, repetimos, precisar en qué porcentaje intervienen en dicha conformación unas gentes u otras. Pero fácil es comprobar que, sea cual sea ese porcentaje, la presencia de lo español propiamente dicho en la topografía biológica, espiritual y social de Brasil es indiscutible. Ofrezco a los etnólogos e historiadores el tema, que merece una honda, meditada y extensa investigación.

Y a partir de este momento, cuando precisamente en Brasil comienzan las inquietudes, primero latentes y tímidas, más tarde po- 
tenciadas por el deseo de forjar definitivamente la nacionalidad absoluta a que los habitantes de la tierra se creían con derecho, que conducirían fatalmente a la independencia, una nueva coordenada se dibuja en el mapa de las relaciones de España con Brasil. Es la coordenada diseñada por los movimientos migratorios, en la que los españoles ocupan, una vez más, un lugar importantísimo desde el punto de vista cuantitativo. El siglo XVIII representa, como hemos visto, el gran paréntesis de los Tratados, durante el cual las fuerzas de consolidación de la etnia brasileña van cuajando. Es, como diría Miguel de Unamuno, un período largo de intrahistoria, en que las masas se van conformando y adaptando al paisaje social y de cultura naciente. Las fuerzas van del hombre a la tierra y de la teirra al hombre, y en este bélico empeño telúrico y existencial se irán dibujando los caracteres específicos de la nueva raza. Las aldeas y ciudades van adquiriendo fisonomía propia. El campo y la ganadería, la mineración y otras empresas avanzan en el sentido de la consolidación, con altos y bajos, marchas y contramarchas, que son imposición del propio avance civilizador. Asistimos, sin que nos demos cuenta de ello, sin verlo, como no vemos la marcha de las agujas de un reloj, a movimientos internos de impresionante profundid, que la Historia - que es la retina humana - no capta con facilidad. Esos movimientos, cuando alcanzan su cénit, contribuyen a la formación del semblante diferenciado de la raza.

Brasil es, como estamos acostumbrados a oir, un país continente. No fueron suficientes las expediciones colonizadoras de los primeros siglos para problar tan vastas soledades. Oliveiros Ferreira, que en su libro Nossa América: Indoamérica habla de esta soledad poblada, escribe: "uma mancha humana aqui, outra ali, e entre ambas o vazio, a zona morta em que o homem não vive, e menos convive. Não é apenas que entre uma mancha humana e outra exista o nada, mas sim que cada uma dessas manchas - qualquer que seja sua situação ou sua magnitude - é densa em seu centro e se desvanece progressivamente ao aproximar-se da periferia" Para aumentar el número de grandes manchas y disminuir las posibilidades de comunicación entre lo que existe entre una mancha y otra - que es el hombre o el grupo social -; para poblar tan anchas soledades telúricas; para incrementar el progreso y explotar las riquezas del suelo - que es el fin o uno de los fines fundamentales del avance humano -; para incrementar el proceso civilizador, el país, como toda América, se vio obligado a importar mano de obra europea. Era urgente poblar estas vastísimas extensiones americanas. Era urgente dominarlas. Y a la población de las mismas concurrieron también los españoles en proporciones que nunca han sido bien precisadas por etnólogos, sociólogos e historiadores, pero que sobrepasan, sin duda, las expectativas, como se observa, incluso, a simple vista. 
A partir de ahora, los españoles van a entrar en la composición étnica brasileña desde la ladera representada por los movimientos migratorios europeos que van a proaucirse durante el siglo XIX y a intensiricarse durante la primera mitad del XX, como consecuencia del desarrollo industrial de las grandes urbes y de la necesidad de atender a ese desarrollo incrementando la base de su subsistencia humana, que es el campo y la ganadería. Durante la época del llamado Brasil Colonia, no se puede hablar de movimientos migratorios propiamente dichos. Los españoles, que a partir de finales del siglo XIX se fijan en suelo brasileño, llegan al país estimulados por una política oficial y deliberada de intensiticar demográticamente la tierra, y las corrientes de emigración se hallan en relación directa con las aspiraciones de quienes, en su propio suelo de origen, no encuentran el horizonte deseado de su evolución y progreso. El emigrante es un desarraigado. Pero el emigrante español y portugues atenúa su sentido del desarraigo al encontrar aquí bases más propicias para su desarrollo existencial, que van desde las propiamente linguísticas hasta las que se retieren al tipo de constitución social que han impuesto en el país sus antepasados. Hasta 1808, la emıgración y la colonización de Brasil era provocada y tenía objetivos politicos y militares. A partir del establecimiento de la Corte portuguesa en esta tierra, los objetivos pasan a ser o a tener un sentido mucho más demográfico que otra cosa, y a las iniciativas del Gobierno se suman las iniciativas privadas, que buscan mano de obra calificada. Aunque teóricamente - como dice José Francisco de Camargo en el capítulo II del volumen II Brasil, a Terra $e$ o Homem, obra dirigida por Aroldo de Azevedo - podamos partir de 1808, por el hecho del Gobierno brasileño haber abierto los puertos a las naciones amigas, las estadísticas oficiales empienzan a ofrecer números más claros a partir de 1820 . Hay que señalar por anticipado, sin embargo, que ninguna de esas estadísticas refleja con exactitud la realidad en este campo, y que las cifras suelen ser muy superiores a las que en ellas se leen.

Entre 1820 y 1883 llegan a Brasil — según las estadísticas más dignas de crédito - 537.501 emigrantes, sin que se pueda precisar con exactitud el número correspondiente a cada contingente extranjero. Durante los siete años comprendidos entre 1884 y 1890 llegan al país aproximadamente 500.000 emigrantes, según señala el autor que acabamos de citar. Sin embargo, Manuel Diegues Junior, en su estudio sobre las Regióes culturais do Brasil, dice que el censo de 1890 acusó la presencia de un número menor, 351.545, inluídos los naturalizados, y observa que los españoles se mantenían en niveles numéricos elevados. Entre 1891 y 1900, cuando entraron aquí 1.129.315 emigrantes, según la estadística que acepta José Francisco de amargo, la emigración española se sitúa en tercer lugar en 
relación a la italiana y portuguesa, y alcanza la cifra de 157119 españoles. Entre 1901 y 1913 se da la cifra más elevada: en ese período, a los españoles les corresponde el 14 por ciento de la población de emigrantes. "Até 1930 - anota el autor citado -, o Brasil recebeu, por decênios, respectivamente, os seguintes contingentes: $671.351,797.744$ e 840.215 imigrantes: portugueses $(32,5 \%)$, italianos $(32,2 \%)$, e espanhóis $(19,3 \%)$, constituiriam os contingentes principais entre 1901 e 1910; no decênio seguinte, os portugueses perfizeram $40,3 \%$ e os espanhóis $21,3 \%$, superando os italianos $(16,8 \%)$ Composição sensivelmente alterada entre $1921 \mathrm{e}$ 1930 , com $34,1 \%$ de portugueses, $12 \%$ de italianos e $9 \%$ de espanhóis" Paul Hugon, en su libro Demografia Brasileira, y Delgado de Carvalho, en su Organização Social e Política Brasileira, dibujan el siguiente cuadro del número de emigrantes españoles por año: 1910: 20.843 ; 1920: 9.136; 1930: 3.218 ; 1940: 409; 1950: 3.808; 1954: 11.338; 1955: 10.738; 1956: 7.921; 1957: 7.680; 1960: $7.662 ; 1961: 9.813 ; 1963: 2.436 ; 1964: 616 ; 1966: 469 ; 1968$ : 743. En la década del 50, como se ve, el número de españoles llegados a Brasil es muy expresivo; representa un $12 \%$ del total de emigrantes llegados a esta tierra. Le mayoría de ellos se fijan en el Estado de São Paulo; concretamente, el 67,7\%, y también en Río, Minas y Rio Grande do Sul. En el cuadro estadístico que dibuja Camargo, que establece la entrada de emigrantes por nacionalidades entre 1820 y 1960 , se consignan las siguientes cifras de españoles: 1820 - 1883: 14.337 (2,6\% - 4\% lugar); 1884: 31.501 ( $7,0 \%$ - 3\% lugar); 1891 - 1900: 157.119 (13,9\% - 3. lugar); 1901 - 1910: 129.341 (19,3\% - 3\% lugar); 1911 - 1920: 169.944 (21,3\% - 2. ${ }^{\circ}$ lugar); $1921-1930: 76.013$ (9,0\% - 3\% lugar); $1931-1940: 9.937\left(3,4 \%\right.$ - 5. ${ }^{\circ}$ lugar $) ; 1941$ - 1945: 275 $(1,5 \%-4 \%$ lugar $) ; 1946-1950: 7.826\left(6,9 \%-4 .^{\circ}\right.$ lugar $)$; 1951 - 1960: $98.547\left(16,8 \%-2 .^{\circ}\right.$ lugar $)$ Es decir, que entre 1820 y 1960 entraron en Brasil 694.740 españoles, lo que representa un porcentaje de $12,8 \%$ en relación a emigrantes procedentes de otras naciones, ocupando el tercer lugar, después de Portugal $(31,8 \%)$ y de Italia $(29,8 \%)$ Dicho cuadro estadístico fue elaborado por el autor teniendo en cuenta los Cuadros Estadísticos de la Dirección de Estadística Económica y Financiera del Tesoro de Rio de Janeiro (1938) y el Anuario Estadístico de Brasil IBGE, Consejo Nacional de Estadística, Rio de Janeiro, de 1947 a 1962. Arthur Ramos - y esto sólo para comprobar la poca fe que merecen las estadísticas se acoge a las estadísticas del Departamento Nacional de Imigração, y cita las siguientes cifras: de 1884 a 1944 entraron en el país 584.060 españoles, distribuidos así por decenios: 1884 - 1893: $103.116 ; 1894-1903: 102.142 ; 1904-1913: 224.672 ; 1914-$ 1923: $94.779 ; 1924$ - 1933: $52.405 ; 1934$ - 1944: 6.946. Claro está que puede observarse un porcentaje constante aproximado 
entre dichas estadísticas, que podría establecerse como índice o común denominador para una investigación más seria. "São Paulo é - Estado - añade Arthur Ramos - que tem recebido o maior afluxo de imigrantes espanhóis. De acordo com os dados do Departamento Estadual do Trabalho, lá entraram 293.916 espanhóis, de 1856 a $1915 \quad \mathrm{O}$ auge do movimento imigratório foi no período de 1902 a 1911, quando entraram no Estado 110.923 espanhóis, número só excedido pelos italianos. Até hoje, os espanhóis ocupam o segundo lugar no movimento imigratório paulista, precedidos pelos italianos, e seguidos pelos portugueses" Estas afirmaciones pertencem a 1947 Luiz Melo Rodriguez, en el capítulo IV del volumen II Brasil, a Terra e o Homem, titulado As etnias brasileiras, destaca también la importancia de este contingente de españoles en el país, los cuales se distribuyeron geográficamente de la siguiente forma, según el censo oficial de 1950 , que estimaba en un total de 131.608 los españoles existentes en Brasil, cifra, sin duda, muy inferior a la realidad: Región Sur: 111.945; Región Este: 17.851; Región Norte: 1.099; Región Centro-Oeste: 474, y Región Noroeste: 373. "Na região Sul - añade - (que congrega $84 \%$ desses espanhóis), destaca-se São Paulo, com 102.671 indivíduos, vindo em segundo lugar o Paraná (7.192) Na região Leste, o predomínio cabe ao Estado da Guanabara (10.814) seguindo-lhe a Bahia (2.473)

Hemos intentado ser objetivos e imparciales. En ningún momento hemos puesto la fantasía por encima de la realidad. Para ello, tuvimos siempre el cuidado de respetar las fuentes de información más serenas y objetivas. La conclusión, que anticipamos, es el resultado de todas esas informaciones, y no creemos que ande muy lejos de la verdad. La verdad, por otro lado, en este tipo de investigaciones, es relativa, porque los procesos de abordaje histórico se resienten de muchas fallas. No obstante, ojalá consideraciones como éstas puedan servir de punto de partida para estudios más anchos y profundos del problema, que son importantísimos para la comprensión del fenómeno contemporáneo de la brasilidad. 